Шаталова Н. И., Осипян И. Ю.

N. I. Shatalova, I. Yu. Osipyan

ТРУДОЛЮБИЕ КАК СТЕРЕОТИП ЭМОЦИОНАЛЬНО-ЦЕННОСТНОГО ОТНОШЕНИЯ К ТРУДУ

\title{
INDUSTRIOUSNESS AS A STEREOTYPE OF EMOTIONAL AND AXIOLOGICAL ATTITUDE TO WORK
}

Шаталова Нина Ивановна - доктор социологических наук, профессор, зав. кафедрой управления персоналом и социологии Уральского государственного университета путей сообщения (Россия, Екатеринбург). E-mail: NShatalova@eka-net.ru.

Ms. Nina I. Shatalova - Doctor of Sociology, Professor, Head of Personnel Management and Sociology Department, Ural State Transport University (Russia, Yekaterinburg). E-mail: NShatalova@eka-net.ru.

Осипян Ирина Юрьевна - аспирант кафедры управления персоналом и социологии Уральского государственного университета путей сообщения (Россия, Екатеринбург). E-mail: IJOsipjan@usurt.ru.

Ms. Irina Yuryevna Osipyan - a postgraduate student, Personnel Management and Sociology Department Ural State Transport University (Russia, Yekaterinburg). E-mail: IJOsipjan@usurt.ru.

Аннотация. В статье делается попытка осмысления феномена трудолюбия. Дано определение трудолюбия как сложного понятия, отражающего глубокое личностное чувство по отношению к труду. Показано, что трудолюбие работника содержательно включает в себя не только морально-нравственные характеристики человека и смысложизненные ценности, но является фактором, определяющим перспективы социальноэкономического развития. Кроме феномена «любовь» в основе трудолюбия заложены и такие моральнонравственные качества личности, как привычка, интерес и уважение к труду. Отсутствие любви к труду является стержнем всех социальных проблем личности и общества. Рассматривается принципиальное отличие трудолюбия от такого феномена, как трудоголизм.

Summary. The article is an attempt to understand the phenomenon of hard work. The definition of diligence as a complex concept, which reflects a deep personal feeling is on-wear to work. It is shown that meaningful employee diligence includes not only the moral characteristics of a person and the meaning of life value, but it is a factor determining the prospects for social and economic development. In addition to the phenomenon of "love", moral and ethical qualities of the person, as a habit, interest and respect for work make up the basis of hard work. The lack of love of work is at the core of all social problems of individuals and society. We consider the fundamental difference between the hard work and workaholism.

Ключевые слова: труд, любовь, интерес, уважение к труду, труд как ценность, нравственное содержание труда, трудолюбие, трудоголизм.

Kew words: work, love, interest, respect for work, work as a value, the moral content of the work, diligence and workaholism

УДК 364.322(075.8)

Трудовая деятельность может осуществляться либо по принуждению (административному, экономическому), либо по внутреннему убеждению, либо по тому и другому. Современные ученые в основном отмечают принудительный характер труда. Но в процессе эволюции труд существенно усложнился: человек стал выполнять все более разнообразные операции, применять все более сложные средства труда, ставить перед собой и достигать более высокие цели. Труд все более приобретает творческий характер, повышается мера ответственности за его результаты, что требует большей свободы действий и самостоятельности. Эти особенности труда в современном производстве требуют гуманистического подхода, усиления внимания к личности каждого человека. В этой ситуации необходимо изучение не только трудового потенциала работника, мотива- 
ции его трудового поведения, но и моральных качеств, характеризующих субъективное расположение личности к труду: смысла трудовой активности, добросовестности, старания, усердия работника. Все это отражается на количестве и качестве общественно полезных результатов.

«В деятельности человека почти всегда присутствует некоторая определяющая черта, устойчивое ядро, вокруг которого концентрируются многочисленные частные проявления его поступков. Этой чертой с древнейших времен является трудолюбие» $[8,19]$. Трудолюбие превращает труд из неприятной обязанности в «первую жизненную потребность» [6, 195]. Социальноэкономическая значимость данного феномена для общества и личности требует внимания к сущности этого понятия.

Начнем с того, что феномен «трудолюбие» на русском языке обозначается сложным словом и включает два таких исключительно важных для человека и человечества понятия, как «труд» и «любовь».

Труд - фундаментальный вид жизнедеятельности человека, основа возникновения и развития личности и всего общества. Он формирует в человеке «устойчивое внутреннее своеобразие» $[1,82]$ и является сферой проявления не только сущностных сил, но и глубоких чувств человека. Труд, работа, приносящие человеку положительные эмоции, повышают его самооценку, способствуют росту способностей, заложенных природой. Труд становится «ареной развития и самореализации личности» $[3,15]$, «абсолютной самоцелью, призванием человека» $[1,82]$. Способности человека проявляются, реализуются и развиваются в процессе разнообразной трудовой деятельности. В человеке есть «неизменный стержень, то есть те его черты, которые накладывают отпечаток на все его поведение» $[5,68]$. Этот стержень формирует трудовая деятельность. Сегодня можно даже сказать, что труд продлевает жизнь: на основании многолетних наблюдений доказано: все долгожители трудятся до конца своих дней, ленивых среди них нет.

Второе понятие, которое описывает феномен трудолюбия, - «любовь». Любовью обычно называют глубоко личное эмоциональное чувство, во многом не предсказуемое, основанное на свободном волеизъявлении, которое отражает духовное восхождение личности, ее самоотдачу. Не случайно древние видели в любви космическую силу, подобную силе тяготения.

«В жизни есть великое счастье и великий труд - любовь», - писал В.А. Сухомлинский. Она представляет собой сложный мотивационный феномен, который насыщен духовностью и нравственностью. Любовь - сила, энергия, средство, способное мотивировать человека для эффективного выполнения своих обязанностей. Любовь чаще всего проявляется в форме оценочного отношения, избирательной активности и потому превращает труд в наиболее плодотворную сферу самореализации личности. Но если любовь между мужчиной и женщиной или любовь к родине опоэтизированы всей мировой культурой, в ней человечество видит высокую космическую силу, то трудолюбию «повезло» гораздо меньше, хотя это чувство по продуктивности и значению в жизни людей не уступает любви двух половин человечества.

Есть все основания определить трудолюбие как своего рода глубокое личное чувство по отношению к труду. Оно включает в себя и жертвенность по отношению к работе, и самоотверженность, и волю к постоянству. Любовь к труду проявляется в состоянии эмоционального подъема, воодушевления, в результате которого человеку интересно то, чем он занимается, он успешно строит карьеру и показывает высокие профессиональные достижения. «В каждом человеке присутствует одна черта, поддерживающая его в продолжении всей жизни: это любовь к тому, над чем он потрудился, во что он вложил часть себя» $[7,132]$.

Любовь эмоционально наполняет труд и преобразует личность как носителя этого чувства, изменяет ее ценностные ориентации. Говоря о детском труде, В.А. Сухомлинский писал: «Трудолюбие - это прежде всего сфера эмоциональной жизни детей. Ребенок стремится работать тогда, когда труд дает ему радость. Чем глубже радость труда, тем больше дети дорожат собственной честью, тем нагляднее видят в деятельности самих себя - свои усилия, свое имя» $[9,208]$. Все эти слова можно с полным правом отнести и к взрослым трудолюбивым людям. Сказанное не означает, что труд для кого-то превращается в развлечение. Он требует напряжения и упорства. В то же время радость труда не сравнима ни с какими другими радостями. 
Шаталова Н. И., Осипян И. Ю.

ТРУДОЛЮБИЕ КАК СТЕРЕОТИП ЭМОЦИОНАЛЬНО-ЦЕННОСТНОГО ОТНОШЕНИЯ К ТРУДУ

Радость немыслима без чувства красоты. Труд сам по себе обладает эстетической ценностью, а не только утилитарно-полезным смыслом. Красота труда - это прежде всего то, что человек создает. Радость труда - это красота бытия, переживая которую человек обретает чувство собственного достоинства, гордость от осознания того, что трудности преодолены. Настоящее чувство радости доступно лишь тому, кто умеет напрягать силы, знает, что такое усталость. Трудолюбие приносит его обладателю поглощенность и наслаждение, сравниться по силе с которым может только плотское наслаждение (это известно каждому трудолюбивому человеку).

Результатом деятельности трудолюбивых людей являются наиболее важные трудовые достижения мира. Трудолюбие - основная энергия мира, так как оно берет на себя его известную дисгармонию с тем, чтобы привести все окружающее в состояние гармонии. Энергия трудолюбия позволяет превратить чужой внешний вещный мир в мир личностный, удобный и приспособленный.

Например, стоит заросшее травой поле. Оно производит унылое впечатление, как и некрасовская «несжатая полоса», хотя на нем растут прекрасные васильки и ромашки. Но приходит землепашец и устраивает так, что земля очищается от сорняков, засеивается зерном и дает урожай, который накормит тысячи людей. Городскому человеку, может быть, кажется, что труд крестьянина неприятен, грязен. Но, как говорит поговорка, «состав земли не знает грязи». Для землепашца это не грязь, а удобная или неудобная, плодородная или неплодородная, готовая или неготовая к вспашке или посеву земля.

Своя поэзия есть в каждом труде: бухгалтер наслаждается видом цифр, в которых, благодаря его работе, сосредоточена вся финансовая информация фирмы; продавец радуется удачно проданному товару, а уборщица с радостью смотрит на чистое помещение, которое она только что привела в порядок.

По нашему убеждению, трудолюбивому человеку труд, которым он занимается, обязательно приносит радость.

В основе трудолюбия лежит инстинкт активности человека. В детстве нет нетрудолюбивых: ребенок активен по своей природе. Само же трудолюбие обслуживает все человеческие потребности - от физиологических (потребности в пище, одежде и т.д.), экзистенциальных (потребность в стабильности, уверенности в завтрашнем дне и др.) до таких социальных, как потребность в привязанности и общении, в уважении и высокой оценке со стороны окружающих. «Человеческая гордость за свой труд - важнейший источник нравственной чистоты и благородства» $[9,207]$.

В основе трудолюбия заложены такие нравственные качества личности, как привычка, интерес и уважение к труду. Человек трудолюбивый ниоткуда не возьмется, если не воспитывать в нем привычку трудиться. Именно привычки являются формой поведения человека и накладывают на него определенный отпечаток. Человек еще в школе начинает впитывать в себя, что учеба - это труд, требующий волевых усилий, внимания, настойчивости и дисциплины. Привычка к труду заставляет человека до конца жизни держать себя в тонусе. Она позволяет ему переносить трудности, которые встречаются в жизни, делать работу, не считаясь с настроением и даже состоянием здоровья.

Важен интерес как целеустремленное отношение человека к своим обязанностям. В человеческой психике интерес проявляется как волевой импульс, направляющий его действия. Интерес к работе является одним из главных мотиваторов в выборе профессии, места работы. «Интерес это механизм, способствующий становлению и развитию всех составных элементов трудолюбия активности, добросовестности, исполнительности» $[8,16]$. Интерес порождает цели и стремление к их достижению.

Если говорить о механизмах формирования трудолюбия, в первую очередь необходимо сказать о способностях. Человек любит ту работу, которая соответствует индивидуальным особенностям его личности. Способный человек более быстро и прочно овладевает необходимыми знаниями и умениями, так как имеет внутренние психические регуляторы, обеспечивающие воз- 
можность их приобретения. Он выполняет работу с бо́льшим удовольствием, чем тот, кто работает по принуждению или рассматривает работу только как источник средств к существованию или средство реализации карьерных устремлений.

На формирование трудолюбия оказывают влияние как среда, коллектив, так и сам процесс труда. Молодой человек, имеющий большие планы на организацию своей трудовой карьеры, попав в коллектив лодырей, очень быстро социализуется как не любящий работать, научится отлынивать от работы не хуже своих старших коллег. И наоборот, трудолюбивый коллектив, в который человек попадает в начале трудовой жизни, создаст правильные ролевые аналоги, которые в будущем станут прочной основой для удачной производственной жизни.

Трудолюбивый человек обычно бывает счастлив, ибо жизнь в избытке предоставляет предмет его увлечения - работу. Как писал Екклесиаст, «Труд глупого утомляет». Счастливое самоощущение приносит также уважение окружающих, которые всегда испытывают потребность в трудолюбивых людях. Кроме того, трудолюбивый человек - самореализованный человек. Преодоление для него связано только с внешними сопротивляющимися объектами. Такие качества трудолюбивого человека, как прилежание и терпение, позволяют преодолевать самые сложные препятствия и решать трудные проблемы. Не случайно все люди, совершившие великие открытия или создавшие великие произведения, говорили, что на 90 \% своим успехам они обязаны именно трудолюбию.

Но есть люди другой крайности, для которых работа заслоняет все жизненные интересы. Их обычно называют трудоголиками. Они большую часть времени проводят на рабочем месте, говорят, думают только о работе, не проявляя интерес к другим сферам жизни. Трудоголики иногда добиваются больших результатов и делают хорошую карьеру.

Трудолюбец, в отличие от трудоголика, не пренебрегает семьей, общением с друзьями. «Трудолюбивый - это самореализующийся человек, это в идеале привлекательная, цельная, просвещенная личность. Человек, работающий не ради одобрения, символов положения в обществе и наград, он стремится работать потому, что любит работу, потому что работа, развивает себя. Трудоголик же может деградировать как личность» $[2,103]$.

Материал, полученный нами, позволяет проиллюстрировать сказанное посредством цифр. Пожалуй, ничто так не различает людей в работе, как трудолюбие или его отсутствие. Зависимость творческой продуктивности от способности личности находить в трудовой деятельности важную сферу самореализации наглядно показана в табл. 1.

Таблица 1

Взаимосвязь трудолюбия личности и ее творческой продуктивности, \%

\begin{tabular}{|c|c|c|c|c|c|c|}
\hline \multirow{2}{*}{$\begin{array}{l}\text { Самооценки } \\
\text { трудолюбия }\end{array}$} & \multicolumn{6}{|c|}{ Самооценки отношения к творческому труду } \\
\hline & $\begin{array}{c}\text { Имеют } \\
\text { творче- } \\
\text { скую } \\
\text { работу }\end{array}$ & $\begin{array}{c}\text { Желали } \\
\text { бы иметь } \\
\text { творче- } \\
\text { скую } \\
\text { работу }\end{array}$ & $\begin{array}{c}\text { Скорее } \\
\text { всего, не } \\
\text { хотят } \\
\text { творче- } \\
\text { ской рабо- } \\
\text { ты }\end{array}$ & $\begin{array}{c}\text { Если бы и } \\
\text { имели } \\
\text { такую ра- } \\
\text { боту, то } \\
\text { отказались } \\
\text { от нее }\end{array}$ & $\begin{array}{c}\text { Работа } \\
\text { является } \\
\text { сферой } \\
\text { самореа- } \\
\text { лизации }\end{array}$ & $\begin{array}{c}\text { Работа не } \\
\text { является } \\
\text { сферой } \\
\text { самореа- } \\
\text { лизации }\end{array}$ \\
\hline Трудолюбивые & 41,1 & 10,8 & 21,5 & 1,9 & 56,8 & 26,2 \\
\hline $\begin{array}{l}\text { Средне трудолю- } \\
\text { бивые }\end{array}$ & 38,0 & 14,7 & 26,0 & 0,7 & 44,9 & 29,1 \\
\hline Нетрудолюбивые & 12,5 & - & 87,5 & - & 37,5 & 25,0 \\
\hline
\end{tabular}


Шаталова Н. И., Осипян И. Ю.

ТРУДОЛЮБИЕ КАК СТЕРЕОТИП ЭМОЦИОНАЛЬНО-ЦЕННОСТНОГО ОТНОШЕНИЯ К ТРУДУ

ка. В наше сложное переходное время 56,3 \% опрошенных, считающих себя трудолюбивыми, указали, что экономический статус их семьи средний и выше. Причем 100\% оценивших себя «не очень трудолюбивыми» определили экономическое положение своей семьи как «довольно бедное», или «очень бедное». В то же время более половины из них не считают, что необходимо проявлять какую-то активность для решения проблем адаптации к рыночным условиям (среди оценивших себя трудолюбивыми таких 14,9 \%).

Пожалуй, можно уверенно сказать, что лень сродни «дурной энергии», которая, будучи абсолютно непродуктивной, постоянно держит человека в состоянии напряжения. Трудолюбие же придает труду особое восприятие как одной из главных жизненных ценностей. Давно доказано, что человек начинает опускаться, когда утрачивает способность работать. Единственное, что нужно сделать, чтобы человек стал деградировать, - не давать ему работать. Не случайно многие пожилые люди, выйдя на пенсию, очень часто начинают резко стареть. Юриспруденция признает, что одна из основных проблем преступника заключается в его неспособности или нежелании работать, и этот факт принимается во внимание при выявлении криминальных наклонностей людей. Наибольшую трудность в борьбе с подростковой преступностью в нашей стране создает когда-то казавшаяся гуманной система, запрещавшая детский труд. Принятая с самыми лучшими намерениями, думается, именно она непосредственно ответственна за подростковую преступность. Недоверие к труду подростка и в особенности запрет на самостоятельную жизнь и зарабатывание денег порождают у подростка чувство, что он лишний, что он уже проиграл, еще не начав свою игру. Чуть позже он избегает воинской обязанности, связанной с большим напряжением сил и умением налаживать отношения, а затем - боится начать собственную карьеру.

В своем большинстве дети хотят работать. Они ходят за матерью или отцом, пытаясь то подать инструменты, то подмести, то постирать свои вещи. Наиболее мудрые взрослые поддерживают это желание детей, проявляют достаточно терпения, позволяя детям помогать им в работе. Ребенок, которому это позволяется, укрепляется в мысли, что его присутствие и помощь важны. В дальнейшем он безболезненно начнет собственную трудовую жизнь. Ребенок, которого насильно готовят к какой-то профессии, заставляют заниматься чем-то, не допуская к сотрудничеству, не давая возможности отвечать за свой труд, убежден, что никому не нужен. Позднее у него возникнут трудности в производственной и семейной жизни. После того, как он прожил в праздности и отрыве от семейных проблем все свое детство, на него вдруг взваливаются обязанности. Ему трудно привыкнуть к этому. Работу он воспринимает как нечто чуждое. Не являясь частью общества, подросток часто противостоит ему.

Наше исследование, на которое мы уже ссылались, показало, что сформированные в застойный период стереотипы отношения к труду в обществе достаточно живучи даже в рыночное время. Более трети опрошенных $(31,8$ \%) на вопрос, должен ли, по их мнению, подросток подрабатывать, ответили, что подросток должен прежде всего учиться. Более того, подросток часто не включен и в семейные трудовые проблемы. Так, в 34 \% семей, имеющих дачные участки, дети не помогают в их обработке; в 24 \% семей дети не помогают даже в уборке квартиры.

Трудолюбие как поведенческий стереотип необходимо отличать от трудовой активности вследствие послушания, повиновения обстоятельствам, внешнему принуждению. В таком поведении видится доля трагизма: человек постоянно находится в состоянии напряжения, в конфликте между тем, что необходимо делать, и потребностью обрести состояние покоя. Обычно с помощью психологической рационализации осознание такого конфликта вытесняется, и конфликт остается в подсознании в форме сильного стресса, невротических симптомов. Здесь мы пришли к мысли о том, что трудолюбие - это еще и основа психического здоровья человека.

Таким образом, трудолюбие - это особое качество поведения личности, которое определяет социальную и функциональную приспособленность работника, обеспечивающую характер, способы и формы трудового поведения. От него во многом зависят мера напряженности самоотдачи личности и степень идентификации с конкретным трудовым процессом. 


\section{ЛИТЕРАТУРА}

1. Вебер М. Избр. произведения / М. Вебер. - М., 1990.

2. Ильин Е. П. Работа и личность. Трудоголизм, перфекционизм, лень / Е. П. Ильин. - СПб.: Питер, 2011.

3. Каверин С. Б. Мотивация труда / С. Б. Каверин. - М.: Изд-во психологии РАН, 1998.

4. Консультирование в управлении человеческими ресурсами: учеб. пособие / под ред. д-ра социол. наук, проф. Шаталовой Н. И. - М.: ИНФРА-М, 2010. - 210 с.

5. Кэтэлин 3. Удовлетворенность трудом: Мнение социолога / 3. Кэтэлин. - М., 1983.

6. Маркс К. Соч. / К. Маркс, Ф. Энгельс. - М.: Государственное издательство политической литературы, 1960. T. 23.

7. Матушкин С. Е. Компетентностные контексты трудолюбия / С. Е. Матушкин // Вестник ОГУ. - № 2 (163). - февраль. - 2014.

8. Матушкин С. Е. Факторы воспитания трудолюбия / С. Е. Матушкин, П. И. Чернецов. - Красноярск: Издво Краснояр. ун-та, 1987.

9. Сухомлинский В. А. Сердце отдаю детям / В. А. Сухомлинский. - Киев: Радянська школа, 1972.

10. Шаталова Н. И. Чувство собственного достоинства и работа / Н. И. Шаталова // Человек и труд. - 2013. № 10. - C. 67-71. 